\title{
ENSINO DA FÍSICA EM MOÇAMBIQUE: DESAFIOS DAS TICs E PRÁTICAS DE ENSINO CENTRADO NO ALUNO
}

\section{PHYSICS TEACHING IN MOZAMBIQUE: CHALLENGES OF ICTS AND STUDENT-CENTRED TEACHING PRACTICES}

\author{
A. G. Fortes ${ }^{1}$, H. A. F. Beirão ${ }^{2}$, Amane Santos ${ }^{1}$ \\ ${ }^{1}$ Universidade Rovuma. \\ ${ }^{2}$ Escola Secundária Geral de Maparra.
}

\begin{abstract}
Resumo
O currículo de Física em Moçambique encontra-se dividido em unidades didáticas que preconizam atividades letivas na sala de aula, em laboratórios e atividades complementares em diversos ambientes, com vista a motivar os alunos e tornar a aprendizagem mais prática. Assim sendo, o artigo objetiva apresentar os desafios do uso das tecnologias digitais de informação e comunicação (TICs) e do ensino de Física centrado no aluno em Moçambique. Trata-se de uma pesquisa descritiva, do tipo estudo de caso, embasada pelo método bibliográfico e questionário, com formulário online, aplicado a 54 professores de Física, de diferentes níveis de ensino. Constatou-se que diversas instituições de ensino em Moçambique não têm laboratórios de ensino, durante a formação dos professores não se fornecem subsídios necessários para o uso das TICs e a aprendizagem voltada ao aluno tem vantagens cognitivas, afetivas e psicomotoras. Conclui-se que com o uso das TICs e práticas de ensino de Física centrado no aluno, pode-se desenvolver laboratórios virtuais para fazer face a demanda de aulas experimentais e tornar a aprendizagem mais fácil, dinâmica e contextualizada. Porém, a fraca expansão das TICs nas zonas rurais é um dos fatores que limita o seu uso no ensino em Moçambique.
\end{abstract}

Palavras-chave: Ensino de Física. Ensino centrado no aluno. Uso das TICs. Moçambique. 


\begin{abstract}
The Physics curriculum in Mozambique is divided into didactic units that recommend teaching activities in the classroom, in laboratories and complementary activities in different environments, to motivate students and make learning more practical. Therefore, the article aims to present the challenges of using information and communication technologies (ICTs) and student-centered Physics teaching in Mozambique. This is a descriptive research of the case study type, based on the bibliographic method and questionnaire, with an online form, applied to 54 physics teachers, from different levels of education. It was found that several educational institutions in Mozambique do not have teaching laboratories, during the training of teachers the necessary subsidies for the use of ICTs are not provided and the learning aimed at the student has cognitive, affective and psychomotor advantages. It is concluded that with the use of ICTs and student-centered Physics teaching practices, virtual laboratories can be developed to meet the demand for experimental classes and make learning easier, dynamic and contextualized. However, the weak expansion of ICTs in rural areas is one of the factors that limit their use in teaching in Mozambique.
\end{abstract}

Keywords: Physics teaching. Student-centered teaching. Use of ICTs. Mozambique.

\title{
I. INTRODUÇÃO
}

$\mathrm{Na}$ atualidade, falar das ciências, das tecnologias de informação e comunicação (TICs) e do ensino centrado no aluno são assunto do momento nas mais diversas áreas de ensino, onde exige-se mudanças curriculares para padrões educacionais mais modernos e contextualizados, caracterizados pela introdução da aprendizagem ativa e significativa de conteúdos clássicos e contemporâneos, respeitando-se os ritmos de aprendizagem do aluno ou grupo de alunos, as criatividades e o desenvolvimento do raciocínio crítico, para fazer face às demandas atuais e a construção de um sistema educacional e de ensino mais firme, dinâmico e de competitividade global.

As mudanças ocorridas no sistema educacional moçambicano, marcado pelo modelo educacional pré-colonial (anterior a 1975) e pelo modelo posterior que passou por dois grandes momentos: um imediatamente pós-colonial, concorrente à guerra civil, entre 1975 e 1992 e o outro após o fim dos conflitos armados, em 1992 que vigora até hoje. Com a estabilidade político-militar e melhoria das condições socioeconômicas do País, sobretudo nas últimas duas décadas, a área de ensino teve vários avanços, porém ainda existem inúmeros desafios a serem ultrapassados.

Entre os avanços pode-se destacar a diminuição da taxa de analfabetismo (de 93\% em 1975 para 56\% em 2019), emancipação do gênero, expansão da rede escolar para áreas rurais, incentivo para a formação, introdução do ensino à distância, diminuição do rácio professor-aluno nas salas de aula (de 79 alunos por professor em 1975 para 60 alunos em 2020) e o ensino primário gratuito, porém ainda se depara com a questão da desvalorização da carreira docente, precariedade das condições de trabalho do professor, ausência de creches e escolas pré-primárias públicas, curto período letivo e a falta de materiais didáticos, experimentais e informáticos (MEDH - MOÇAMBIQUE, 2020). 
Estes desafios exigem, tanto no professor como no aluno, a busca de novas formas de disseminação do conhecimento por meio do ato de ensinar e o modo de aprender, visto que, a relação ensino e aprendizagem é construída por meio de vários fatores que funciona como o conjunto de competências e habilidades individuais, que passam por um processo de mudança de comportamento tanto daquele que ensina, como daquele que aprende. Assim sendo, a aprendizagem centrada no aluno pode impulsionar a ação individual na obtenção do saber, construindo o caminho para novos questionamentos e reflexões originais (PINHEIRO; BATISTA, 2018).

O processo de ensino e aprendizagem (PEA) nas ciências naturais, particularmente da Física, com auxílio das novas TICs é uma temática recorrente e atual em todos os níveis de ensino. Sendo a Física, ciência de fundamental importância no advento da era do conhecimento e propulsora da revolução tecnológica que atualmente molda o cotidiano, as TICs constituem um meio didático inevitável e mostra-se importante na aprendizagem, pois faculta simultaneamente como sendo biblioteca, laboratório, meio de pesquisa intercomunicação e mais (HECK, 2017; MOREIRA, 2017).

No ensino moçambicano, as matérias da Física são introduzidas gradualmente, ainda no ensino primário (equivalente ao ensino fundamental I brasileiro), na disciplina de Ciências Naturais, agregando ainda, os conteúdos da Química e Biologia. De forma autônoma, a Física é disciplina de formação geral, incluída na grade curricular do ensino secundário geral (ESG), do primeiro ciclo (ESG1, inclui a 81, 91 e 101 classes equivalente ao ensino fundamental II), parte do segundo ciclo (ESG2, a $11 \nmid$ e $12 \nmid$ classes equivalente ao ensino médio) e em alguns cursos técnico-médios e universitários.

Assim sendo, o presente estudo teve como objetivo apresentar os desafios do uso das TICs no ensino de Física em Moçambique e conhecer os fatores que influenciam nas práticas de ensino de Física centrado no aluno. O estudo começa por contextualizar o cenário atual do uso das TICs no ensino da Física, que se encerra com uma breve descrição dos desafios e possibilidades para um ensino centrado no aluno como forma de tornar o PEA da física mais significativa e abrangente, voltada ao cotidiano do aluno.

\section{RESUMO DE LITERATURA}

\section{II.1. Ensino de Física em Moçambique: dados históricos}

Pode-se traçar a história da Física a partir do momento em que a humanidade começou a ver e analisar os fenômenos naturais de modo racional, abandonando explicações místicas ou divinas. As primeiras tentativas racionais de explicação da natureza vieram com os indianos e com os gregos antigos. A Filosofia Natural, como era conhecida a Física, confundia-se com a química e com certos aspectos da matemática e biologia, e pode ser considerada a disciplina acadêmica mais antiga, ao considerar sua presença na astronomia (BIZZO, 1992). Para além destes, os chineses, egípcios, ingleses, alemães e americanos foram determinantes no desenvolvimento da Física experimental.

Em Moçambique, a história e o PEA de Física estão vinculados ao processo histórico e evolutivo da educação moçambicana, concretamente nos processos e trajetos sobre a sua inserção nos currículos escolares e as visões que têm sido dadas ao ensino desta ciência ao 
longo da história educacional do país. Nas primeiras décadas do século $X X$, a abrangência da escola era muito restrita. De fato, o projeto do País colonizador (Portugal) tinha no trabalho forçado sua principal base de sustentação econômica e política, justificando-o e tornando-o aceitável, através do corolário da educação e civilização do indígena (RIBEIRO, 2015).

Cabaço (2009) descreve o sistema educacional colonial como:

Um sistema unificado a todo império pelo modelo em vigor na metrópole. Na escola primária, em Moçambique, estudava-se, até meados da década de 1960, em textos que se referiam à vida rural em Portugal, sua vegetação, sua fauna, sua paisagem, seus usos e costumes. Era a tentativa de alienação física do espaço sociocultural e da natureza que cercava a criança das colônias. As disciplinas de História e Geografia, Física, Humana e Económica, que se prolongavam por todo o ensino médio, referiam-se as questões de Portugal, visando a comprometer deliberadamente o universo da imaginação e mitificar a metrópole (CABAÇO, 2009, p. 15).

Após a independência nacional, em 1975, e sobretudo depois dos primeiros anos da década dos anos 90, houve uma expansão massiva de instituições de todos os níveis de ensino, em todo o território nacional. Este processo contribuiu para o desenvolvimento sociocultural e económico do País, possibilitando a inovação tanto das práticas comuns, como da ciência e da tecnologia (TERENCIANO; NATHA, 2016).

Atualmente, o sistema de ensino de Física em Moçambique ainda se fundamenta no ensino livresco, conteudista e centrado na transmissão de conhecimentos, que Langa (2015) caracterizou como o ensino centrado no docente, que privilegia o método de transmissão vertical (docente para estudante), estruturado em torno da sala de aulas. O professor verbaliza explicações de conceitos apresentados nos livros didáticos, resolve e propõe exercícios de fixação. A investigação, a experimentação e as demonstrações representam atividades subsidiárias que, quando se faz, ocorre quando sobra algum tempo após a atividade principal, dar-aulas.

\section{II.2. O PEA de Física e as TICs}

Atualmente, ensinar Física é uma tarefa que exige do professor agilidade, habilidade e aperfeiçoamento profissional para desenvolver métodos de ensino que atraiam os alunos para novas descobertas e desenvolvimento dos conhecimentos empíricos.

Com o grande avanço das TICs que vem ocorrendo de forma acelerada no mundo atualmente, a área de educação tem sofrido grande influência. As TICs dentro do ambiente escolar são dinâmicas interdisciplinares, integrando os saberes das TICs e da educação (HECK, 2017). Assim sendo, o professor deixará de ser apenas um observador e transmissor de conteúdo, passando a ser um facilitador ou ajudante no PEA, buscando uma aprendizagem mais significativa para seus alunos.

Em relação ao PEA auxiliado com o uso das TICs, o principal objetivo seria a melhoria da qualidade de ensino e a promoção de maior interação entre alunos e aluno-professor, 
auxiliando deste modo, na compreensão de conceitos abstratos, visto que os estudantes podem alterar variáveis e verificar as mudanças resultantes, além da contribuição pedagógica que os modelos trazem para a compreensão de conceitos teóricos (LARA et al., 2011). Além disso, o uso de TICs e metodologias ativas nas aulas de Física, permitem exceder a concepção empirista que entende o conhecimento unicamente surgido a partir da observação e relaciona o conteúdo a ser estudado com os conhecimentos prévios dos alunos (VIVEIRO; CAMPOS, 2014).

Na prática escolar, os professores sentem cada vez mais o descompasso no domínio das TICs e tentam segurar o máximo que podem, fazendo pequenas concessões, sem mudar o essencial. Alguns professores têm medo de revelar sua dificuldade diante do aluno, por isso e pelo hábito mantêm uma estrutura repressiva, controladora, repetidora. Estes percebem que precisam mudar, mas não sabem bem como fazê-lo e não estão preparados para experimentar com segurança. Muitas instituições exigem mudanças dos professores sem dar-lhes condições para que eles as efetuem (MORÁN, 2015).

Por isso, a integração das TICs no ensino, não pode ser confundida como máquina de ensinar, mas sim como ferramenta educacional, que consiste na complementação e aperfeiçoamento do aprendizado (SILVA et al., 2018). As TICs estão avançando a passos largos, fazendo-se presente em diversas atividades humanas, e sendo necessário, portanto, o conhecimento mínimo desses recursos existentes para aprimorar o trabalho do professor, como meio auxiliar na construção do conhecimento.

As TICs não substituem o professor, mas modificam algumas das suas funções. A tarefa de passar informações pode ser deixada aos bancos de dados, livros, vídeos, programas em CD. O professor se transforma agora no estimulador da curiosidade do aluno por querer conhecer, pesquisar, buscar a informação mais relevante. Por outro lado, coordena o processo de apresentação dos resultados pelos alunos. Depois, questiona alguns dos dados apresentados, contextualiza os resultados, adapta-os à realidade dos alunos, questiona os dados apresentados. Transforma informação em conhecimento e conhecimento em saber, em vida, em sabedoria o conhecimento com ética (MORAN, 2011, p. 125).

Podemos elencar aqui, os vários meios disponíveis para o uso educacional no ensino de Física, porém o grande centro dessa temática é o modo de como o professor fará uso, com a qualidade esperada, desses meios. Ou seja, não adianta só disponibilizar as melhores e mais modernas ferramentas tecnológicas às escolas é preciso conhecer estratégias para melhor integrá-las, assim tirar maior proveito para o PEA e aproximar a sala de aula do universo do aluno (HECK, 2017; SILVA et al., 2018).

Medeiros e Medeiros (2002) destacam que, devido ao fato de a aprendizagem em Física exigir alto grau de abstração, as simulações e animações computacionais, apesar de não se constituírem em solução final para os desafios de se ensinar conceitos científicos, podem ser úteis aos PEA, sobretudo quando não existe os laboratórios de ensino tradicional. Por isso, os professores devem aproveitar esse momento para usar a tecnologia a seu favor, são muitos os recursos à disposição, basta escolher o que mais se adapta à sua necessidade 
(SILVA et al., 2018).

Em contrapartida, a falta de infraestruturas laboratoriais para aulas de informática nas escola moçambicanas, déficit de computadores e sinal da internet, dificuldades em manusear os equipamentos tecnológicos por parte dos professores e a falta de energia elétrica constituem os principais constrangimentos para utilização das TICs no ensino. Neste âmbito, Langa (2015) e Silva et al. (2018) sugerem palestras interativas, passeios e visitas guiadas, discussões, jogos ao ar livre, brincadeiras e promoções de eventos científicos locais para envolver o aluno e trazer o conteúdo para sua realidade.

As atividades experimentais e demonstrativas, no geral, compõem um dos aspectoschave do PEA de Física, pois apresentam uma oportunidade de desenvolvimento cognitivo, onde se observa e relaciona com o fenômeno em estudo. Assim sendo, quando se usam as TICs para a demonstração lúdica dos fenômenos, estes auxiliam na tomada de decisões e inserção social, visto que, aprimoram a observação, a paciência e a curiosidade, numa dimensão que transcende o contexto escolar.

\section{II.3. Ensino de Física centrado no aluno}

O ensino centrado no aluno é aquele em que o professor trabalha como estimulador, no qual, os alunos são os que se expressam, enquanto o professor fala apenas quando for necessário sugerir a forma como os alunos devem abordar e trabalhar o conteúdo. A opção por metodologias de ensino centrado no aluno implica o uso de estratégias que favoreçam interação, discussão, negociação de significados entre colegas, apresentação oral do produto de suas atividades colaborativas, receptividade à crítica, expressão de suas ideias e sugestões relacionadas às atividades de seus pares (MOREIRA, 2018).

Diversos autores criticam as práticas instrumentais no ensino, sugerindo, deste modo, um ensino centrado no aluno, onde este desenvolve as competências para encarar os desafios da vida adulta. Libâneo (1994) considera que é preciso apostar no

(...) ensino centrado na realidade social, em que o professor e alunos analisam problemas e realidades do meio socioeconômico e cultural, da comunidade local, com os seus recursos e necessidades, tendo em vista a ação coletiva frente a esses problemas e realidades (LIBÂNEO, 1994, p. 67).

Para isso,

O aluno deve ser ativo, não passivo. Ela ou ele tem que aprender a interpretar, a negociar significados; tem que aprender a ser crítica(o) e aceitar a crítica. Receber acriticamente a narrativa do bom professor não leva a uma aprendizagem significativa crítica, a uma aprendizagem relevante, de longa duração; não leva ao aprender a aprender (MOREIRA, 2010, p. 6).

O ensino centrado no aluno não deve, ou não deveria receber a interpretação de ser um modo de ensinar no qual o aluno tem total liberdade de aprender apenas aquilo que escolhe 
aprender. Um evento educativo sempre envolve um facilitador (ensino), um determinado conhecimento (currículo), alguns alunos (aprendizagem) e ocorre em um ambiente social (contexto). Todavia, esse currículo não pode ser definido como uma série de conteúdos pré-definidos que devem ser narrados aos alunos ou depositados dentro de suas cabeças. Alunos precisam receber opções e tratar desses conteúdos em situações que lhes façam sentido e lhes sejam significativas. Cabe aos alunos decidir se desejam aprender algum conteúdo de forma significativa (MOREIRA, 2010, 2018).

$\mathrm{Na}$ atualidade o ensino de ciências, particularmente da Física, deve estar centrado no aluno com vista a desenvolver competências científicas, como a modelagem, comunicação, argumentação e validação, em prol da aprendizagem significativa de conteúdos clássicos e contemporâneos (MOREIRA, 2017). Neste sentido, o professor deve se empenhar em desenvolver habilidades para estimular o aluno a conhecer a Física.

Moreira (2017) e Moreira (2018) citam as formas como podemos facilitar o aluno a aprender a aprender criticamente: (i) aprender/ensinar perguntas em lugar de respostas (Princípio da interação social e do questionamento); (ii) aprender a partir de distintos materiais educativos (Princípio da não centralidade do livro de texto); (iii) aprender que somos preceptores e representadores do mundo (Princípio do aprendiz como perceptor/representador); (iv) aprender que a linguagem está totalmente envolvida em todas as tentativas humanas de perceber a realidade (Princípio do conhecimento como linguagem); (v) aprender que o significado está nas pessoas, não nas palavras (Princípio da consciência semântica); (vi) aprender que o ser humano aprende corrigindo seus erros (Princípio da aprendizagem pelo erro); (vii) aprender a desaprender, a não usar conceitos e estratégias irrelevantes para a sobrevivência (Princípio da desaprendizagem); (viii) aprender que as perguntas são instrumentos de percepção e que as definições e as metáforas são instrumentos para pensar (Princípio da incerteza do conhecimento); (ix) aprender a partir de diferentes estratégias de ensino (Princípio da não utilização do quadro de giz. Do abandono da narrativa).

\section{METODOLOGIA}

A pesquisa foi realizada através da abordagem qualitativa e descritiva, do tipo estudo de caso. Segundo Martins (2017), a pesquisa qualitativa explora as particularidades e os traços subjetivos (opiniões, motivos, aspirações, crenças, valores e atitudes) específicas de um pequeno grupo, em relação a uma situação vivenciada por ele, neste caso, os desafios do uso das TICs e práticas de ensino centrado no aluno na disciplina de Física em Moçambique.

Em função dos objetivos, Martins (2017) classifica a pesquisa como descritiva, visto que tem por finalidade descrever as características de uma população, ou seja, as práticas de ensino centrado no aluno e os desafios do uso das TICs nas aulas de Física, envolvendo o uso de técnicas padronizadas de coleta de dados, caso do questionário. A pesquisa também foi um estudo de caso, que na ótica de Yin (2005), refere-se a um tipo de pesquisa bastante específica, detalhada e exaustiva de um único objeto, o que permite obter um conhecimento aprofundado dele, porém seus resultados não podem ser generalizados, atendo-se apenas ao caso em estudo.

Realizou-se ainda, a pesquisa bibliográfica para descrever, a partir de teorias e estudos anteriores: (i) o histórico do ensino de Física em Moçambique; (ii) o PEA de Física e as 
novas TICs; (iii) e o ensino de Física centrado no aluno. A revisão bibliográfica baseou-se na leitura de livros, artigos científicos, teses e dissertações, sem delimitação temporal e espacial das publicações, porém com afinidades contextuais.

Aplicou-se um questionário, cujas questões foram divididas em duas partes: (i) perfil dos professores: gênero, faixa etária, tempo de serviço, nível de formação acadêmica e o nível de ensino que leciona; (ii) questões acadêmicas e letivas: característica do laboratório da escola, importância do uso das TICs na aula de Física, a formação dos professores e habilidades no uso das TICs, e as vantagens do uso de metodologias de ensino de Física voltada ao cotidiano dos alunos.

Neste estudo, constituiu amostra, 54 professores de Física que lecionam nos diferentes níveis de educação moçambicana. A amostragem foi probabilística aleatória simples. Segundo Yin (2005) neste tipo de amostragem, todos os elementos que compõem a população alvo têm a mesma probabilidade de serem selecionados para a amostra, em função da disposição no preenchimento do formulário durante o período que decorreu a pesquisa, de 7 de setembro a 23 de outubro de 2020. Depois, realizou-se a compilação e as análises estatística e de conteúdo, seguindo as fases: seleção inicial de dados, a análise e interpretação dos resultados.

\section{RESULTADOS E ANÁLISES}

A descrição do perfil dos professores (tabela 1) foi realizada analisando-se as questões referentes ao gênero, idade, tempo de trabalho como professor de Física, nível de formação acadêmica e psicopedagógica ${ }^{1}$ e nível de ensino que leciona.

\footnotetext{
${ }^{1} \mathrm{~A}$ psicopedagogia é uma área do saber científico que estuda os processos relacionados com a aprendizagem humana. O conhecimento da Psicopedagogia ajuda o professor a compreender a maneira como o indivíduo aprende, as condições necessárias para aprender, o que aprende e o que permite que ele realmente aprenda (MARTINS et al. 2018). Por isso, em Moçambique, um dos requisitos para admissão na carreira docente é ter formação psicopedagógica.
} 


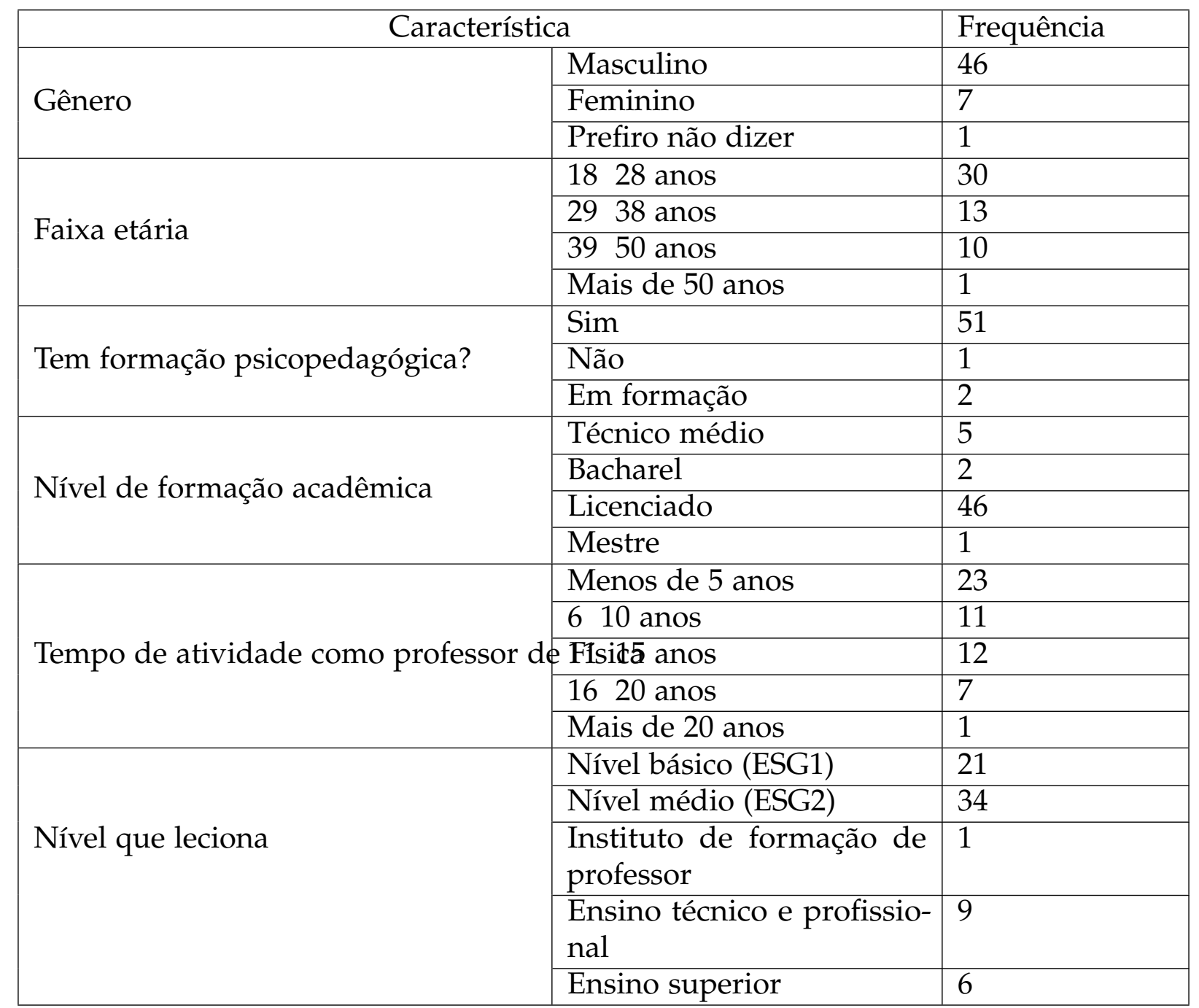

Tabela 1: Perfil dos professores de Física.

Fonte: Os autores.

A pesquisa identificou que a maioria das instituições de ensino, secundário e superior, em Moçambique (Figura 1) não dispõem de laboratório de ensino (53,7 \%). Entre as instituições que têm, 20,4 \% estão em condições razoáveis, 18,5 \% em condições obsoletas ou desatualizados e apenas 7,4 \% das instituições possuem laboratórios de ensino/pesquisas devidamente equipados e atualizados. 


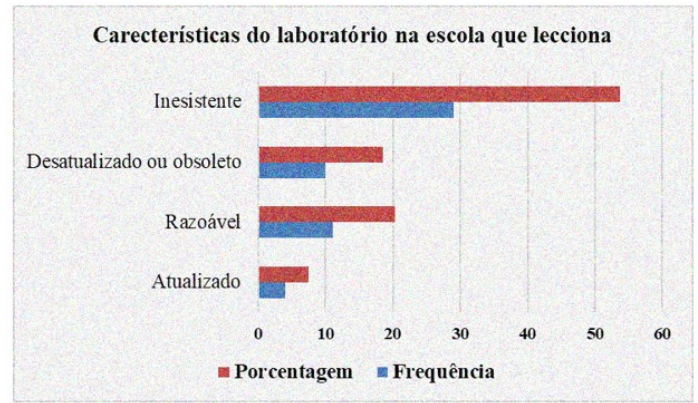

Figura 1: Características dos laboratórios de Física nas escolas secundárias, institutos de formação de professores e universidades moçambicanas.

Fonte: Autores.

Na questão sobre a importância do uso das TICs no ensino de Física os professores podiam escolher mais de uma opção. Assim sendo, houve uma dispersão nas respostas (Tabela 2), entre elas: ajuda no professor a ganhar o tempo de lecionação (55,6\%), isto é, o professor consegue atingir seus objetivos com maior brevidade possível; possibilitam uma aprendizagem mais eficiente agindo como catálise da atenção e estímulo à interação (53,7 \%); pode-se aprender em qualquer local, não sendo imperioso estar em uma sala de aulas (44,4\%); a aprendizagem torna-se mais rápida, assimilável e divertida (35,2\%); e é possível observar os fenômenos estudados (29,6 \%). Porém 1,9 \% apontaram não ser importante o uso das TICs no ensino de Física devido a sua fraca expansão, não sendo possível aplicar tais tecnologias em zonas rurais, por carecerem de corrente elétrica e acessibilidade à internet.

\begin{tabular}{|l|l|l|}
\hline \multicolumn{2}{|c|}{ Importância do uso das novas tecnologias no ensino de Física } & $\begin{array}{l}\text { Porcen- } \\
\text { tagem } \\
(\%)\end{array}$ \\
\hline $\begin{array}{l}\text { O professor não perde muito tempo escrevendo no } \\
\text { quadro e ganha tempo explicando os conteúdos }\end{array}$ & 30 & 55,6 \\
\hline São proveitosas e divertidas & 12 & 22,2 \\
\hline A aprendizagem pode ocorrer em diversos ambientes & 24 & 44,4 \\
\hline Tornam os conteúdos mais práticos e fáceis & 25 & 46,3 \\
\hline A aprendizagem se desenvolve de forma mais rápida & 19 & 35,2 \\
\hline Permite observar o mundo sob diferentes maneiras & 18 & 33,3 \\
\hline $\begin{array}{l}\text { Permite observar os fenômenos e animações com pe- } \\
\text { quenas a um modelo }\end{array}$ & 16 & 29,6 \\
\hline $\begin{array}{l}\text { Possibilidade de trabalhar em grupo ou individual- } \\
\text { mente }\end{array}$ & 14 & 25,9 \\
\hline $\begin{array}{l}\text { Aumenta a atenção e estimula a interação entre alunos } \\
\text { e aluno-professor }\end{array}$ & 29 & 53,7 \\
\hline $\begin{array}{l}\text { Aumenta a motivação e torna o ambiente escolar insti- } \\
\text { gante e atrativo }\end{array}$ & 22 & 40,7 \\
\hline
\end{tabular}

Tabela 2: Importância do uso das novas TICs no ensino de Física.

Fonte: Os autores. 
Quanto aos subsídios técnicos adquiridos durante a formação, a maior parte dos professores de Física (56 \%) declararam estar preparados para uso das TICs no ensino (Figura 2A), pois a sua formação forneceu subsídios técnicos suficientes para tanto (Figura 2B). Por outro lado, 20 \% dos professores declararam não estar preparado para uso das TICs no ensino e 24 \% mostraram-se indecisos, declarando talvez (Figura 2A), mostrando que $26 \%$ dos cursos de formação de professores não forneceram subsídios técnicos suficientes para o efeito e 15 \% mostraram-se indecisos (Figura 2B).

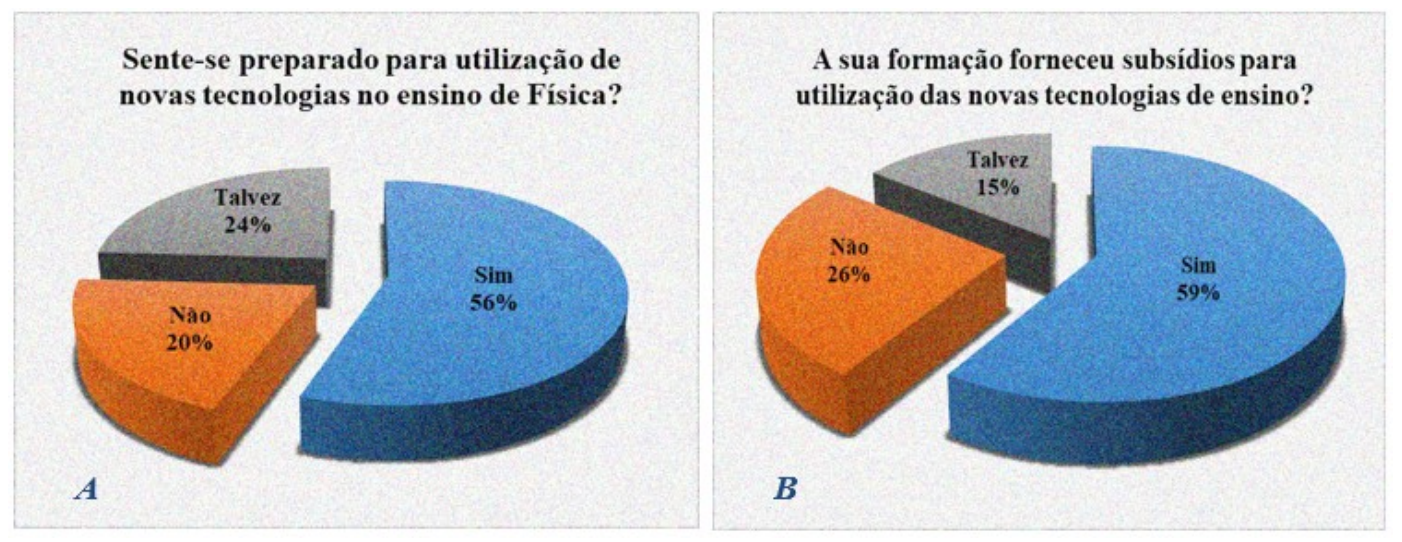

Figura 2: Nível de formação: (A) se sente preparado para uso das TICs no ensino de Física; (B) se a formação fornece subsídio para uso das TICs no ensino de Física.

Fonte: Autores.

Os professores de Física que referiram possuírem subsídios durante a sua formação no uso das TICs no ensino, apontaram que fazem o uso de:

- computadores, sites especializados em ensino de Física e Datashow para a visualização e projeção de vídeos de experiências e demonstrações de ocorrência de certos fenômenos. Os vídeos mais projetados são de Física nuclear e atômica;

- quadros inteligentes, tablets, telefone celular, Sala de aula da Google (Google Classroom), moodle e laboratório virtual para disponibilização de materiais e vídeos experimentais de temas sem condições para realizar nos laboratórios didáticos;

- Google Meet e Zoom para encontros virtuais, discussão de matérias complementares e seções de dúvidas de matérias lecionadas na sala de aula;

- tabuleiros de circuitos elétricos, que facilita aprendizagem e auxilia na motivação dos alunos;

- software Java, Graphmatica e Crispy Plotter na construção e interpretação de gráficos nas unidades temáticas de cinemática, dinâmica, estática e mais;

- simulador de movimentos Freeware para o estudo da cinemática, dinâmica do corpo rígido, conservação de energia, máquinas simples e mais;

- aparelho de rádio para o estudo da propagação das ondas sonoras. 
Quanto às vantagens em utilizar metodologias de ensino centradas no aluno e que refletem o cotidiano do aluno, as respostas dos professores dividiram-se em três domínios, nomeadamente, cognitivo, afetivos e psicomotor (tabela 3):

\begin{tabular}{|c|c|}
\hline Domínio & Vantagem \\
\hline \multirow{5}{*}{ Cognitivo } & Melhora na qualidade de ensino com oferecimento de aulas prática; \\
\hline & $\begin{array}{l}\text { Diminui a distância entre o conhecimento empírico, do dia a dia dos alunos, } \\
\text { por meio de abordagens científicas; }\end{array}$ \\
\hline & $\begin{array}{l}\text { Ajuda na motivação e na compreensão dos fenômenos ao nosso redor: a } \\
\text { ciência está em tudo, nos fenômenos naturais e artificiais; }\end{array}$ \\
\hline & $\begin{array}{l}\text { Os alunos gostam de aprender assuntos relativos ao seu cotidiano. Isso } \\
\text { motiva e torna-os mais ativos e interessados com a ciência; }\end{array}$ \\
\hline & $\begin{array}{l}\text { Demonstrar que a ciência também está nas coisas simples, até as altas } \\
\text { tecnologias do nosso cotidiano e a nossa volta. }\end{array}$ \\
\hline \multirow{7}{*}{ Afetivo } & $\begin{array}{l}\text { Facilita na integração da matéria no aluno, por meio de exemplos e age } \\
\text { como meio de conciliar a teoria da prática; }\end{array}$ \\
\hline & Mostra no aluno que a ciência estuda está presente no seu cotidiano; \\
\hline & Propicia a aprendizagem contínua do aluno em qualquer ambiente; \\
\hline & Facilita a integração e torna os alunos mais interativos no PEA; \\
\hline & $\begin{array}{l}\text { A abordagem dos fenômenos do cotidiano dos alunos facilitar a aprendiza- } \\
\text { gem, aumentam sua autoestima e possibilitar maior interação na aula, por } \\
\text { ele tem certo conhecimento sobre a matéria; }\end{array}$ \\
\hline & $\begin{array}{l}\text { O aluno se familiariza facilmente com a matéria, a aplicação dos conteúdos } \\
\text { e aprende a trabalhar de forma independente ou coletiva; }\end{array}$ \\
\hline & Ensino de Física de forma lúdica. \\
\hline \multirow{3}{*}{ Psicomotor } & Uso de material local na produção de material didático laboratorial; \\
\hline & $\begin{array}{l}\text { Desenvolvimento de habilidades de autodescobrimento de melhores respos- } \\
\text { tas a seus problemas cotidianos e no modo de interpretá-los; }\end{array}$ \\
\hline & experiências como forma de aproximar a teoria da prática. \\
\hline
\end{tabular}

Tabela 3: Vantagens do ensino de Física voltado a realidade do aluno, segundo os objetivos de aprendizagem. Fonte: Os autores.

\section{IV.1. Análise dos resultados}

As análises (tabela 1) indicam que os professores que lecionam a disciplina de Física em Moçambique são maioritariamente jovens, do gênero masculino (88,19 \%), menores de 28 anos (56 \%), licenciados (85\%) e com formação psicopedagógica (94\%) e com menos de cinco anos de trabalho $(42,5 \%)$.

Tradicionalmente, os cursos de Física e Ensino de Física em Moçambique têm um percentual do gênero masculino maior que o gênero masculino, variando entre $1012 \%$ do total de ingressantes por ano (MCTESTP, 2017). Este fato é motivado pela desigualdade de gênero, questões socioculturais e estereótipos de gênero no ambiente escolar. Esta desigualdade se reflete nitidamente na frequência de professoras lecionando a Física nas escolas. Assim sendo, ensinar Física em Moçambique é visto como sendo uma prática profissional específica para o gênero masculino. No entanto, a diminuição deste rácio passa 
necessariamente pela criação de políticas sociais e econômicas que incentivam estudantes do gênero feminino a frequentar os cursos na área de Ciência Naturais e promovam a igualdade de gênero no preenchimento das vagas, sobretudo nas instituições de ensino superior públicas. Por outro lado, a nível das escolas, as alunas, os professores e gestores educacionais podem auxiliar a contornarem este dilema, dado que as sinergias atuais, estão em prol da igualdade de gênero.

A idade dos Professores de Física reflete o perfil etário da população moçambicana caracterizado por uma pirâmide com estreitamento acentuado aos 19 anos e esperança de vida média de 59 anos de idade (INE, 2019). Dados dos Planos Quinquenais do Governo de 2010-2014 e de 2015-2019 e do Plano do setor da educação 2020-2029 mostram que foi ação prioritária do governo desde 2010, expandir o sistema educativo em todo o País, sobretudo os níveis e subníveis com maior pressão de demanda e com crescimento rápido (MEDH, 2020). Para isso, houve diversos programas de formação de professores, houve introdução gradual do ensino a distância no ensino secundário geral (ESG), do 1ž ciclo, seguindo para

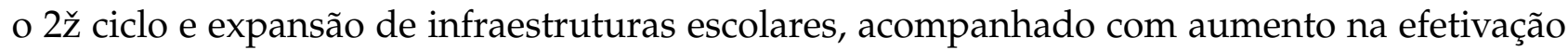
dos professores na função pública.

Segundo MEC/INDE (2007), o ESG deve ser lecionado por professores com a formação superior que são formados pelas universidades e institutos politécnicos, em cursos com duração que variam entre 3 e 5 anos para a licenciatura. E no Ensino Superior, o professor devia ter níveis de pós-graduação (mestre e doutor), mas pela falta de profissionais formados na área de Física, os licenciados ainda lecionam neste nível.

O ESG é o nível que demanda mais professores de Física em Moçambique (Tabela 1). Tal fato pode ser explicado por ser o nível introdutório do ensino da disciplina no país e possuir maior número de estudantes segundo a pirâmide de formação acadêmica (MCTESTP, 2017, p. 17), associado às exigências da obrigatoriedade da inclusão da disciplina de Física na grade curricular de quase todas as classes que compõem o ESG.

A maioria das instituições de ensino no País (Figura 1) carece de laboratórios de ensino/pesquisa, que possam complementar a aprendizagem e investigação dos alunos e professores. O Ministério de Educação tem um projeto de compra de livros escolares de distribuição gratuita, de aquisição de materiais laboratoriais e de formação de professores a todo nível (MEDH, 2020), porém a abrangência dos materiais laboratoriais a nível nacional ainda é insatisfatória. Apesar disso, alguns professores não abandonam as aulas experimentais, praticando através de materiais alternativos (de baixo custo e fácil acesso) e construção de modelos ilustrativos.

As TICs são meios bastantes importantes para a gestão de tempo de aulas e no auxílio do professor de Física no PEA (Tabela 2). No entanto, Moçambique necessita de políticas transformadoras no sistema de educação para uma educação que estabeleça o elo entre TICs e Ciências, de modo a fazer face às tendências atuais, que refletem o contexto político, socioeconômico e tecnológico local e as tendências regionais e global. Tal transformação, passa necessariamente pela instalação de mais salas de estudo das TICs e capacitação do professor no âmbito das TICs, de modo a criar mais possibilidades de o aluno descobrir respostas para os mais diversos desafios complexos do mundo contemporâneo.

Sabendo que o PEA de Física deve propor uma relação entre o conhecimento científico e o cotidiano do aluno, o uso das TICs para visualização de fenômenos e experiência 
complexas (Tabela 2) possibilita uma maior atenção por parte dos alunos, despertando suas curiosidades e tornando a aprendizagem mais divertida, para além de se sentirem desafiados à descoberta da disciplina de Física que antes era subjetivamente tão distante de sua realidade (SANTOS; OLIVEIRA, 2012).

Porém, na realidade moçambicana, existem vários alunos e professores sem domínio mínimo das tecnologias digitais, associado a algumas instituições de ensino que não dispõem de materiais didáticos e recursos técnicos e tecnológicos para as aulas, o que dificulta, de algum modo, no uso das TICs nas aulas de Física. Para os professores, a problemática ainda pode ter causas no próprio processo de formação (Figura $3 \mathrm{AB}$ ), as condições no local de trabalho e a falta de condições financeiras para adquirir um notebook, tablet, telefone celular e estes estarem ligados a internet. Estas dificuldades ocasionam certa comodidade e resistência ao ensino tradicional, onde o professor é o transmissor de conhecimentos padronizados e os alunos, os receptores passivos.

Face às deficiências no processo de formação de professores de Física (Figura 2 AB). Bezerra et al. (2009) consideram que pelo caráter abstrato no ensino da Física, seria necessário ao professor, uma melhor preparação para executar com sucesso esse trabalho. Isso resulta na dificuldade de lidar com o desenvolvimento cognitivo do aluno, deixando a Física cada vez mais distante da realidade do aluno, impedindo assim, o incentivo à prática desse conhecimento.

Santos e Oliveira (2012) sugerem que as TICs podem ser usadas para acesso aos laboratórios virtuais e leitura de textos complementares (Tabela 2), contribuindo, deste modo, para suprir parte dos efeitos da falta que os laboratórios de ensino e bibliotecas escolares convencionais criam, sobretudo para a escolas em zonas rurais e pobres. Por outro lado, pode-se usar as TICs para melhorar a autoestima do aluno e a possibilidade de aprender no ambiente escolar e extraescolar, conectado em grupos ou individualmente. O professor, neste modelo de ensino, desempenha a função mediadora, arquitetando e estimulando a curiosidade dos alunos.

Há concordância nas vantagens em utilizar metodologias de ensino que refletem o cotidiano do aluno (tabela 3), visto que tendem a tornar as aulas de Física mais atraentes e o conteúdo mais efetivo para o aluno, pois este, para além de usar fórmulas e resolver exercícios, quer compreender o mundo que o cerca. Por outro lado, esta metodologia torna possível, para o aluno, utilizar o conhecimento adquirido em sala de aula, adquirindo capacidade para resolver problemas futuros (BEZERRA et al., 2009). Desse modo, o aluno não irá apenas seguir receitas ou reproduzir conceitos, fórmulas e atitudes, mas tomará decisões a partir das ferramentas fornecidas durante sua formação. Para tanto, é necessário atuar na busca pelo seu próprio conhecimento.

\section{CONCLUSÃO}

A sociedade atual vive uma dinâmica social e tecnológica que impactam significativamente nas práticas pedagógicas e de ensino das ciências. Estas práticas foram descritas no trabalho como uso das TICs no ensino de Física e ensino centrado no aluno, representando neste contexto, as ferramentas e metodologias de ensino que dinamizam a aprendizagem e o próprio PEA, no geral. 
A Física é tida como uma disciplina difícil, por estar bastante vinculada a matemática e distante da realidade dos alunos. Em diversas instituições de ensino em Moçambique não existem laboratórios de ensino/pesquisa, o que limita seus alunos a realizarem experiências e demonstrações de leis e teorias científicas e a observação de fenômenos físicos no ambiente laboratorial, dificultando deste modo, a aprendizagem da Física a partir de fatos e repulsa generalizada em relação a disciplina.

Devido a questões socioculturais, políticas e econômicas, a disciplina de Física, no ensino secundário e superior moçambicano é lecionada, maioritariamente, por professores jovens, do gênero masculino, licenciados, com formação psicopedagógica e com menos de cinco anos de experiência na atividade docente.

Alguns professores de Física usam várias TICs na lecionação das aulas, adequando-as em função ao conteúdo de ensino, os objetivos de aprendizagem e as condições locais. Porém, parte dos professores não utilizam as TICs por não estarem preparados, pois suas formações não forneceram subsídios técnicos suficientes para tal, associado a insuficiência de recursos nas instituições de ensino que lecionam.

O uso das TICs no ensino de Física possibilita uma aprendizagem mais eficiente agindo como catálise da atenção e estímulo à interação, proporciona a aprendizagem em ambiente escolar e extraescolar, tornando a aprendizagem mais rápida, assimilável e divertida, possibilitando a observação de fenômenos estudados. Porém, um dos fatores que limita o uso das TICs no ensino de Física em Moçambique é a sua expansão limitada, sobretudo nas zonas rurais, sem internet e energia elétrica da rede.

A aprendizagem voltada ao aluno tem vantagens nos domínios: (i) cognitivo, por contribuir na motivação, a ligação ciência e o cotidiano e melhorar a qualidade do ensino; (ii) afetivo, por facilitar a integração do aluno, proporcionar a aprendizagem contínua, através das situações do cotidiano; (iii) psicomotor, por ajudar na manipulação de materiais, no autodescobrimento e demonstração das teorias científicas.

Conclui-se que o uso de ambientes virtuais de aprendizagem, através das TICs e o ensino centrado no aluno é um dos maiores desafios no PEA de Física em Moçambique. Com as TICs pode-se desenvolver laboratórios virtuais para fazer face a demanda de aulas experimentais devido à falta de laboratórios, que facilitará a integração dos alunos e professores, tornando o PEA de Física mais fácil, dinâmico e contextualizado.

\section{REFERÊNCIAS}

BEZERRA, D. P.; GOMES, E. C. S.; MELO, E. S. N.; SOUZA, T. C.; A evolução do ensino da física perspectiva docente. Scientia Plena, v. 5, n. 9, p. 18, 2009.

BIZZO, N. História da ciência e ensino: onde terminam os paralelos possíveis? Tendências na educação em ciências, v. 11, n. 55, 1992. CABAÇO, J. L. Moçambique: identidade, colonialismo e libertação. São Paulo-SP: Editora UNESP, 2009.

HECK, C. Integração de tecnologia no ensino de física na educação básica: um estudo de caso utilizando a experimentação remota móvel. Dissertação de Mestrado em Tecnologia da Informação e Comunicação. Universidade Federal de Santa Catarina. Araranguá-SC, 2017. 
Instituto Nacional de Estatística (INE). IV Recenseamento geral da população e habitação: Resultados definitivos Moçambique. Maputo: Instituto Nacional de Estatística, 2019.

LANGA, P. Ensino Superior em Moçambique: Caracterização e Desafios. Palestra alusiva à celebração do décimo aniversário do Jornal o País, Centro de Estudos Brasileiros, 18 de Maio de 2015. Anais. Maputo: Jornal o País, 2015.

LARA, A. L.; MANCIA, L. B.; SABCHUK, L.; MIQUELIN, A. F.; PINTO, A. E. A. O PIBID, o ENEPC e os trabalhos sobre as tecnologias de informação e comunicação no ensino de ciências: algumas reflexões e possíveis relações. VIII Encontro Nacional de Pesquisadores em Ensino de Ciências. Anais...Campinas, SP: ABRAPEC, 2011.

LIBÂNEO, J. C. Didática: teoria da instrução e do ensino. In: Didática. 2. ed. São Paulo-SP: Cortez Editora, 1994. p. 5176.

MARTINS, J. Metodologia da Pesquisa Científica. Rio de Janeiro, RJ: Editora Dowbis, 2017.

Ministério da Ciência e Tecnologia, Ensino Superior e Técnico-Profissional (MCTESTP). Estudantes matriculados, graduados e ingressos segundo a area cientifica Ensino Superior. Maputo: Ministério da Ciência e Tecnologia, Ensino Superior e Técnico-Profissional, 2017.

Ministério de Educação e Cultura/Instituto Nacional de Desenvolvimento da Educação (MEC/INDE). Plano Curricular do Ensino Secundário Geral (PCESG) Documento Orientador, Objectivos, Política, Estrutura, Plano de Estudos e Estratégias de Implementação. Maputo: MEC e INDE, 2007.

MEDEIROS, A.; MEDEIROS, C. F. DE. Possibilidades e Limitações das Simulações Computacionais no Ensino da Física. Revista Brasileira de Ensino de Física, v. 24, n. 2, p. 7786, 2002.

Ministério da Educação e Desenvolvimento Humano (MEDH). Plano Estratégico da Educação 2020-2029. Por uma Educação inclusiva, patriótica e de qualidade. Maputo: Ministério da Educação e Desenvolvimento Humano, 2020.

MORÁN, J. Mudando a educação com metodologias ativas. In: SOUZA, C. A. DE; MORALES, O. E. T. (Eds.). Coleção Mídias Contemporâneas. Convergências Midiáticas, Educação e Cidadania: aproximações jovens. 2. ed. Ponta Grossa: UEPG/PROEX, 2015. p. 1533.

MORAN, J. M. Las nuevas tecnologías y el re-encantamiento del mundo. Aletheia, v. 3, n. 1, p. 120127, 2011.

MOREIRA, M. A. Abandono da narrativa, ensino centrado no aluno e aprender a aprender criticamente. VI Encontro Internacional e III Encontro Nacional de Aprendizagem Significativa. Anais...São Paulo-SP: APSIGNIFICATIVA, 2010. 
MOREIRA, M. A. Grandes desafios para o Ensino da Física na educação contemporânea. Revista do Professor de Física, v. 1, n. 1, p. 113, 2017.

MOREIRA, M. A. Ensino de Física no século XXI: desafios e equívocos. Revista do Professor de Física, v. 2, n. 3, p. 8094, 2018.

PINHEIRO, M.N.; BATISTA, E. C. O aluno no centro da aprendizagem: uma discussão a partir de Carl Rogers. Revista Psicologia Saberes, v. 7, n. 8, p. 7085, 2018.

RIBEIRO, F. B. Educação e ensino de História em contextos coloniais e pós-coloniais. Mneme - Revista de Humanidades, v. 16, n. 36, p. 2753, 2015.

SANTOS, I. T. C.; OLIVEIRA, C. A. DE. O ensino de Física mediado pelas tecnologias de informação e comunicação. VI Colóquio Internacional Educação e Contemporanedade. Anais...São Cristovão - CE: EDUCON, 2012.

SILVA, D. M. DA; TAVARES, C. V. F.; SILVA, A. M. DA. O uso da tecnologia como meio auxiliar para o ensino da física: uma abordagem geral sobre sua importância e possibilidades. Congresso Internacional de Educação e Tecnologias. Anais...São Carlos, SP: CiET e EnPED, 2018.

TERENCIANO, F.; NATHA, M. Ensino Superior em Moçambique: Evolução e Indicadores da Avaliação da Qualidade. Revista Electrónica de Investigação e Desenvolvimento (REID), v. 1, n. 7, p. 7994, 2016.

VIVEIRO, A. A.; CAMPOS, L. L. Formação inicial de professores de ciências: reflexões a partir das abordagens das estratégias de ensino e aprendizagem em um curso de licenciatura. Alexandria: Revista de Educação em Ciência e Tecnologia, v. 7, n. 2, p. 221249, 2014.

YIN, R. K. Estudo de caso: planejamento e métodos. 2. ed. Porto Alegre: Bookman, 2005. 